\title{
Letter
}

\section{Family Matters: How Immigrant Histories Can Promote Inclusion}

\author{
SCOTT WILLIAMSON New York University Abu Dhabi
}

CLAIRE L. ADIDA University of California, San Diego

ADELINE LO University of Wisconsin-Madison

MELINA R. PLATAS New York University Abu Dhabi

LAUREN PRATHER University of California, San Diego

SETH H. WERFEL Independent Researcher

\begin{abstract}
Tmmigration is a highly polarized issue in the United States, and negative attitudes toward immigrants are common. Yet, almost all Americans are descended from people who originated outside the country, a narrative often evoked by the media and taught in school curricula. Can this narrative increase inclusionary attitudes toward migrants? We draw from scholarship showing that perspectivetaking decreases prejudice toward out-groups to investigate whether reminding Americans about their own immigration history increases support for immigrants and immigration. We propose that priming family experiences can indirectly stimulate perspective-taking and induce empathy toward the out-group, which we test with three separate survey experiments conducted over two years. Our findings show that priming family history generates small but consistent inclusionary effects. These effects occur even among partisan subgroups and Americans who approve of President Trump. We provide evidence that increased empathy for immigrants constitutes one mechanism driving these effects.
\end{abstract}

$\mathbf{T}$ he idea of the United States as an immigrant nation is a powerful component of American identity, featuring prominently in elite and popular discourse across the ideological spectrum (e.g., Schildkraut 2007; Shiffman 1996). Nonetheless, opposition to immigration also pervades American public opinion and has polarized in recent years (Wong 2016). In this context, a growing experimental literature evaluates strategies for increasing inclusive

Scott Williamson (D), Postdoctoral Associate, Division of Social Science, NYU-Abu Dhabi, srw9498@nyu.edu.

Claire L. Adida (D), Associate Professor, Department of Political Science, UC San Diego, cadida@ucsd.edu.

Adeline Lo (D), Assistant Professor, Department of Political Science, University of Wisconsin-Madison, aylo@wisc.edu.

Melina R. Platas (i), Assistant Professor, Division of Social Science, NYU-Abu Dhabi, mplatas@nyu.edu.

Lauren Prather (D), Assistant Professor, School of Global Policy and Strategy, UC San Diego, LPrather@ucsd.edu.

Seth H. Werfel (D), Independent Researcher, swerfel@alumni.stanford.edu.

This project was supported by generous funding from a University of California, San Diego Divisional Research Grant. The material is also based upon work supported by the National Science Foundation Graduate Research Fellowship Program under Grant No. DGE-114747. We thank participants at workshops at ADRES Lyon, the American Political Science Association Annual Meeting, the European University Institute of Florence, Humboldt University, IAST Toulouse, Jéco Lyon, MPOSS, the University of British Columbia, and the University of Copenhagen for their feedback. All errors are our own. Replication files are available at the American Political Science Review Dataverse: https://doi.org/10.7910/DVN/5UEEU2.

Received: February 14, 2020; revised: November 03, 2020; accepted: November 12, 2020. First published online: December 21, 2020. attitudes toward immigrants (e.g., Adida, Lo, and Platas 2018; Hopkins, Sides, and Citrin 2019).

Our paper evaluates whether the immigrant histories of American families can generate more favorable views of immigration. We argue that reminding Americans of their families' immigration history increases empathy for current migrants to the United States by inducing perspective-taking indirectly. ${ }^{1}$ In turn, this heightened empathy improves views of immigrants as people and increases acceptance of open immigration policies. While far from capturing the full social inclusion of migrants ${ }^{2}$, inclusionary attitudes represent important first steps, with meaningful policy implications. We follow Okamoto and Ebert's (2016) characterization of migrant inclusion as host support for migrants.

We test this argument using three survey experiments in which respondents were reminded about their immigrant pasts either before or after answering questions about their views of immigration. Across three online samples between 2017 and 2019, we find that the treatment increased support for open immigration policies and improved favorability toward immigrants. These effects occurred among Republicans and Democrats, among supporters and opponents of Republican

\footnotetext{
${ }^{1}$ This theory cannot generalize to Native Americans, who were forcibly displaced by such immigration, and it may not capture the experiences of African Americans whose ancestors were forcibly brought to the United States.

${ }^{2}$ We understand inclusion as ranging from "the right to a modicum of economic welfare and security to the right to share to the full in the social heritage ... according to the standards prevailing in the society" (Marshall 1964, 79).
} 
President Trump, and regardless of when respondents' families came to the United States. In the third study, we investigate and find evidence that increased empathy is one mechanism driving our results.

Our paper makes empirical contributions to three strands of literature. First, much research showing that perspective-taking induces empathy relies on resourceand time-intensive interventions (e.g., Broockman and Kalla 2016; Simonovits, Kezdi, and Kardos 2018) and uses explicit instructions to consider the other person's perspective (Todd and Galinksy 2014). We show that a light-touch intervention embedded in an online survey with no explicit perspective-taking instruction can increase empathy as well.

Second, we build on insights from social psychology that perspective-taking can be induced indirectly via shared experience or personal attachment (Batson and Shaw 1991), and we add to the empirical evidence that family connections shape political attitudes (Glynn and Sen 2015). Existing work suggests that family effects may be mediated by their ability to raise empathy for another group - for example, women - but do not provide evidence that speaks directly to this claim. Our analysis indicates that empathy constitutes at least one mechanism through which family connections can have important political implications.

Third, we extend a growing literature on increasing migrant inclusion (Adida, Lo, and Platas 2018; Dinas, Fouka, and Schlapfer Forthcoming), which has real-world implications. The strategy of emphasizing Americans' immigrant roots has often been used by politicians and NGOs seeking to increase popular support for immigration in the United States, and this narrative is found in the curricula of America's public schools. Our results provide empirical evidence that this approach can be successful at shaping Americans' immigration attitudes and is worth pursuing further in advocacy and educational work.

\section{FAMILY HISTORY AND AMERICAN SUPPORT FOR IMMIGRATION}

Nearly all Americans descend from people who came from elsewhere, whether by force or by choice. This history is an important component of American identity: narratives of an American "melting pot," in which individuals of various nations and creeds all become Americans, have existed since the 1700s (Fraga and Segura 2006). While emphasis on the melting pot has at times meant prioritizing white and Protestant cultural norms, advocacy for a more explicitly multicultural American identity gained strength in the mid-twentieth century (Vecoli 1996). Today, large majorities of Americans perceive "incorporationism"-respect for cultural difference - as a key component of American identity (Schildkraut 2007). This idea of the United States as an immigrant nation is commonly reflected in the rhetoric of politicians and immigration advocates (Shiffman 1996), in addition to school curricula (Hilburn, Journell, and Buchanan 2016).

However, the importance of immigration to American identity also coexists with anti-immigrant attitudes
(Wong 2016), which are motivated by perceived threats to the economy (Dancygier 2010) and cultural identity (Hainmueller and Hopkins 2014). Scholars interested in understanding how to reduce migrant exclusion have evaluated the effects of providing information to weaken perceptions of such threats, with mixed results (e.g., Hopkins, Sides, and Citrin 2019).

An alternative strategy to reduce anti-migrant sentiment involves leveraging emotions - especially empathy, the ability to feel another's mental state and/or concern for their plight (Todd and Galinsky 2014). Research indicates that individuals displaying more empathy hold more positive attitudes toward immigrants (Hartman and Morse 2020). Additionally, an individual is most likely to feel empathy for another when they are capable of reflecting on that person's perspective (Batson and Shaw 1991); indeed, interventions that actively encourage perspective-taking reduce out-group prejudice (Simonovits, Kezdi, and Kardos 2018).

Many perspective-taking studies explicitly instruct research subjects to reflect on others' experiences, whether by imagining themselves in their shoes or imagining their feelings. ${ }^{3}$ However, perspective-taking can also be induced indirectly via shared experience or personal attachment to someone like a family member (Batson and Shaw 1991). Individuals are more likely to engage in perspective-taking when they have personal experience with a similar situation or share a bond with that person (Galinsky and Mosowitz 2000).

We suggest that priming family experiences indirectly stimulates perspective-taking and may therefore induce empathy toward the out-group. Several studies demonstrate that familial relationships affect individuals' decision making and attitudes. Washington (2008) finds that having a daughter increases a congressperson's likelihood of voting liberally. Glynn and Sen $(2015,37)$ show that U.S. Courts of Appeals judges who have daughters "consistently vote in a more feminist fashion on gender issues than judges who have only sons," and Sharrow et al. (2018) demonstrate that men become more supportive of sex-equity policies when their first child is female.

We argue that the immigrant stories within many American families can generate empathy-and thus more inclusive attitudes-toward migrants. When Americans are encouraged to remember how their families came to the United States, and the hardships they may have faced when doing so, this shared family experience with contemporary immigrants makes it easier to take their perspective and empathize with them. Likewise, when Americans are reminded of their personal attachment to previous immigrants, they should feel closer to contemporary migrants, facilitating perspective-taking and strengthening empathy. This heightened empathy can lead to more inclusive attitudes toward today's migrants.

\footnotetext{
${ }^{3}$ Todd and Galinsky note that imagine-self and imagine-other treatments do not produce meaningful differences, suggesting that how perspective-taking is activated may not be crucial for influencing attitudes (Todd and Galinsky 2014, 375).
} 
FIGURE 1. Priming Family History Increases Support for Open Immigration
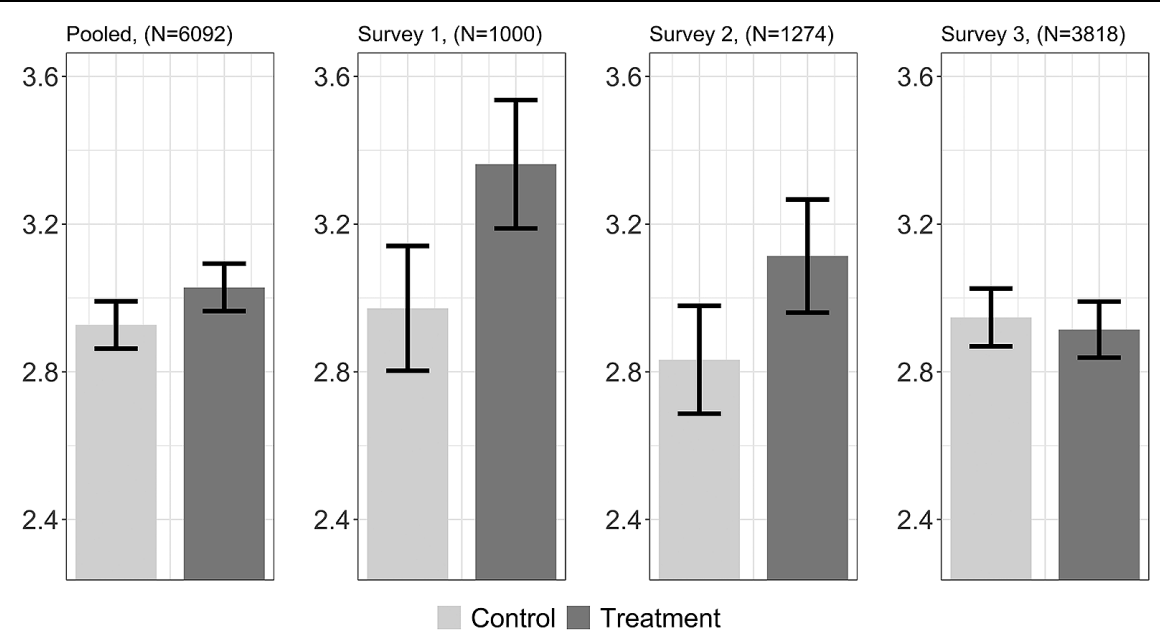

Note: Displays mean responses by treatment group for the following question: Do you agree or disagree that the United States should limit the number of immigrants entering the country? Scale ranges from 1 to 7 , with 7 indicating support for more open immigration (95\% confidence interval).

\section{RESEARCH DESIGN}

We designed an experiment to test whether priming Americans on their own immigrant histories increases support for open immigration policies and improves views of immigrants. The experiment was implemented in three separate studies using online surveys between 2017 and 2019 (SI-B). While the first two studies were not preregistered, they consistently showed an effect of priming family history. We therefore developed and preregistered a third study to explicitly test this effect and the role of empathy as a mediator. The third study was longer than the first two and focused squarely on refugees and immigration. ${ }^{4}$ Research design details, summary statistics, balance tests, tests of heterogeneous treatment effects, IRB approval, and the preanalysis plan are in the SI.

In each survey, respondents were randomly assigned with equal probability to receive a question about their family history (Which was the first generation in your family to arrive in America? ${ }^{5}$ ) either before or after the outcome questions. The first outcome question $-D o$ you agree or disagree that the United States should limit the number of immigrants entering the country?gauges respondent support for more open immigration policies. On the second and third surveys, we included

\footnotetext{
${ }^{4}$ The preanalysis plan can be found here: https://osf.io/cx2zp.

${ }^{5}$ The first study asked about the first generation to immigrate. The second and third studies used the language above to reflect the experiences of African American descendants of slavery as well. Native Americans were not included in the experiment. In the third survey, the question included an additional sentence: Take a moment to think about your own family history. Which was the first generation in your family to arrive in America? Respondents were also asked in the third survey if they knew why their families had come to the United States. These slight variations in design allow us to check whether the treatment is robust to different wording.
}

an additional outcome question: On a scale from 0 to 100, how do you feel about immigrants in the United States? For the third survey, we also ask - prior to the outcome questions - to what extent respondents agree with the statement: I empathize with the reasons people want to immigrate to the United States, as well as the hardships they face when coming to this country. We use these responses to conduct a mediation analysis of empathy with the methods proposed in Baron and Kenny (1986) and Imai, Keele, and Tingley (2010).

\section{RESULTS}

We estimate main effects using difference in means with two-sample $t$-tests. The results are consistent when using OLS regression with control variables and robust standard errors. ${ }^{6}$

Figure 1 presents the difference in means for the open immigration outcome. Across all studies, the family history treatment increased support for more open immigration from an average of 2.93 in the control group to 3.03 in the treatment group $(p=0.025)$, a change of 0.06 standard deviations. This treatment effect is statistically significantly different from zero in Studies 1 and 2 but not in Study 3.

Figure 2 displays the difference in means for the feeling thermometer outcome included in the second and third studies. For the pooled data, the average response increased from 56.74 in the control group to 59.15 in the treatment group $(p=0.003)$, a 2.40 point increase equivalent to 0.08 standard deviations. This result holds in both individual studies.

The effects are relatively small, but similar in magnitude to those in related experiments, particularly in

\footnotetext{
${ }^{6}$ See SI. Both analyses were preregistered for the third study.
} 


\section{FIGURE 2. Priming Family History Improves Favorability of Immigrants}
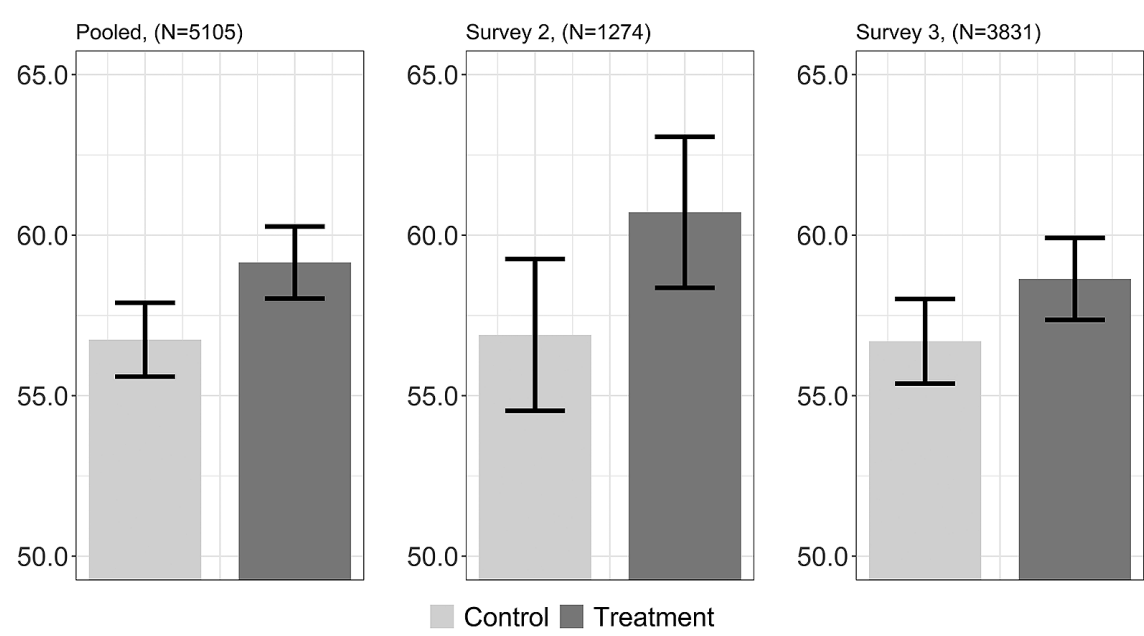

Note: Displays mean responses by treatment group for the following question: On a scale from 0 to 100, where 0 means "completely unfavorable" and 100 means "completely favorable," how would you describe your views of immigrants in the United States? (95\% confidence interval).

the first and second studies (e.g., Dinas, Fouka, and Schlapfer Forthcoming; Kalla and Broockman 2020). Kalla and Broockman, for example, report effect sizes of 0.07 to 0.11 standard deviations in their study on attitudes toward unauthorized immigrants.

Our treatment was less effective in the third study. This difference may have occurred because the survey was significantly longer than the other two, and entirely about attitudes toward migrants: answering prior questions about migrants may have anchored respondent attitudes. ${ }^{7}$ But it could also be a function of the fact that perspectivetaking treatments are less likely to influence policy preferences and more likely to shape explicit evaluations of the "specific person whose perspective is taken" (Todd and Galinsky 2014, 375), which is precisely what we capture with our thermometer outcome.

Finally, the average treatment effect is not driven by specific subgroups, but rather it seems to be general and shared. Indeed, the effect on attitudes toward immigration or the feeling thermometer is not conditional on Republican partisan identity or support for Republican President Trump (as shown in Figure 3), nor is it conditional on racial identity, dispositional levels of empathy, or immigrant generation (SI-E).

\section{TESTING THE EMPATHY MECHANISM}

Perspective-taking can reduce exclusion through several mechanisms including generating empathy, shaping attributional thinking, or increasing self-out-group merging (Todd and Galinsky 2014). Since the relevant mechanisms have implications for understanding how

\footnotetext{
${ }^{7}$ We evaluate the likelihood of finding our Study 3 effect if the true effect were the one uncovered in Study 2. In SI-I, Figure I8, we show that the coefficient in Study 3 falls within the $95 \%$ coverage interval.
}

prejudiced attitudes change and how our treatment may be applied in the real world, we test whether one of these mechanisms, heightened empathy, mediated our treatment effect.

First, we analyzed open-ended responses to our question from the third survey in which respondents were asked to explain why their families came to the United States. ${ }^{8}$ Recall that perspective-taking can be induced through shared prior experience and attachment with the other (Batson and Shaw 1991). If so, we might expect that respondents would be able and willing to describe the specific motives behind this migration and that many of them would mention specific family members who migrated.

More than $40 \%$ of respondents were willing to answer the open-ended question, ${ }^{9}$ with frequent responses including seeking "a better life" and "opportunity," in addition to "escaping" situations such as "persecution." Likewise, many respondents mentioned family-oriented

\footnotetext{
${ }^{8}$ Although most Americans have multiple immigration histories upon which they could reflect (e.g., Waters 1990), some including both voluntary and involuntary migration, very few respondents (3.2\% of sensible responses) mentioned more than one migration story. This is likely due to question wording in that we asked respondents about the "earliest" generation to arrive in the US. We also find that references to slavery are not treatment dependent.

${ }^{9}$ Respondents who are racial minorities, are highly educated, and male, are more likely to answer the open-ended question, but this is not significantly correlated with treatment. Furthermore, there is no significant correlation between respondents' baseline level of empathy and their likelihood of answering the open-ended question, nor between the interaction of baseline empathy and our family history treatment and the likelihood of answering the open-ended question. This is consistent with our theory that, regardless of baseline levels of empathy, empathy can be elicited via a perspectivetaking cue, which has implications for individuals' attitudes toward migrants and migration.
} 


\section{FIGURE 3. Family History Treatment Effects by Partisanship and Trump Approval}
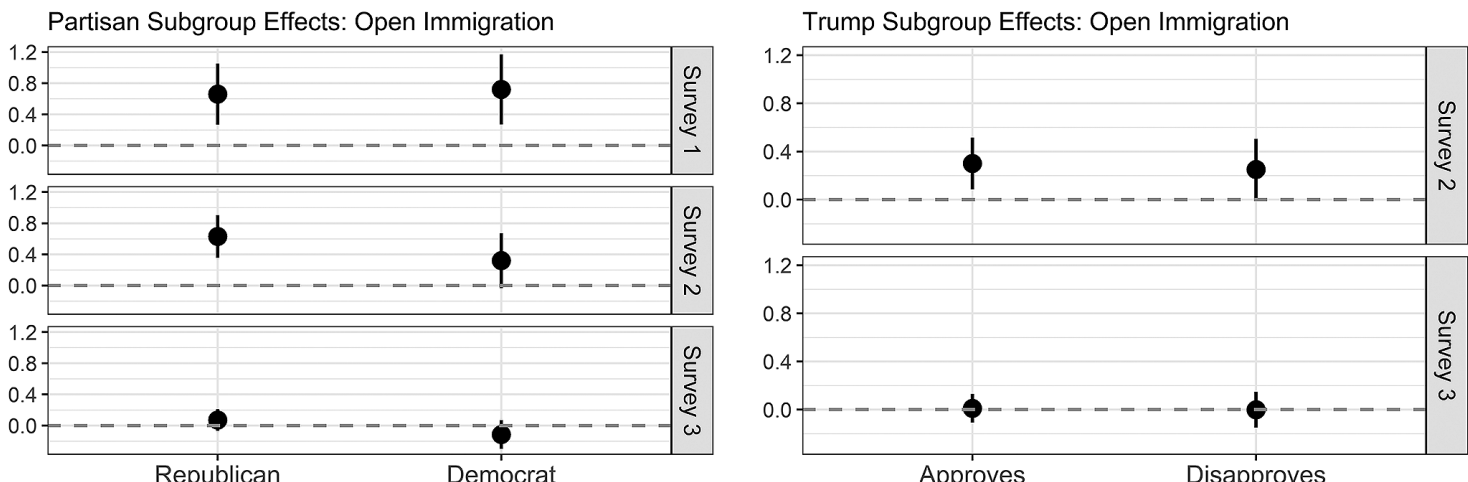

Partisan Subgroup Effects: Thermometer

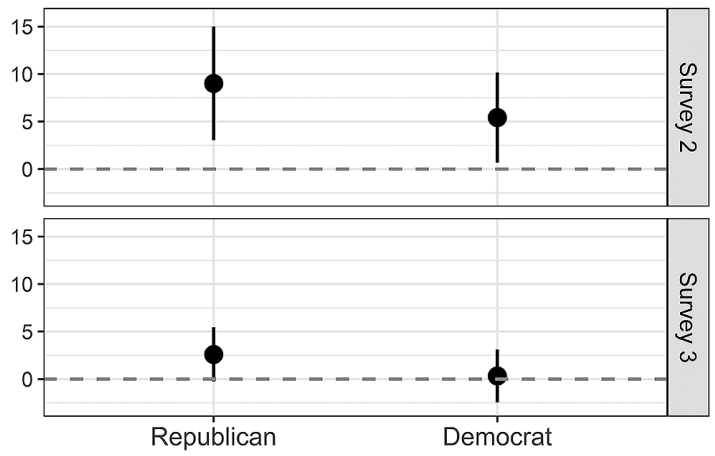

Trump Subgroup Effects: Thermometer

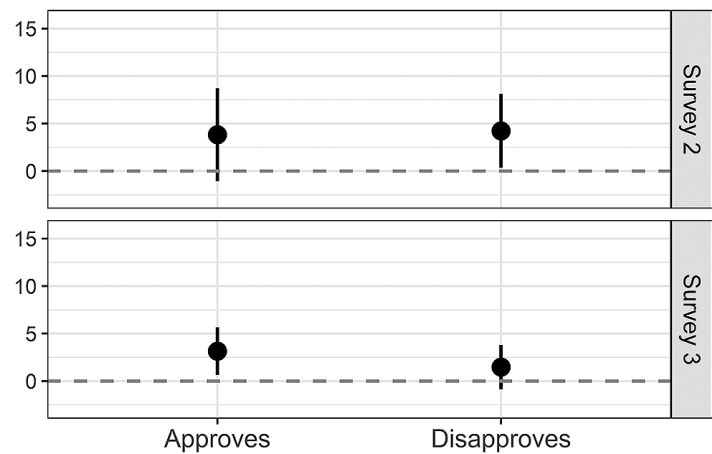

Note: Each coefficient is the treatment effect within the specified subgroup. OLS regression models (95\% confidence interval).

terms such as "grandfather" and "children," especially if they reported more favorable attitudes toward migrants on the feeling thermometer. By priming Americans to think about their family history, our treatment reminded respondents of shared familial experiences and attachments with immigrants (SI-J).

Second, we systematically tested the empathy mechanism. To our knowledge, no other study has explicitly tested whether empathy mediates the relationship between a perspective-taking treatment and attitudes toward migrants. ${ }^{10}$ Our third study does just that. This section reports on our mediation analysis, relying on Baron and Kenny's (1986) analytical approach as well as the method designed by Imai, Keele, and Tingley (2010). While the latter analysis was not preregistered, it constitutes a more generalized version of Baron and Kenny and allows us to conduct sensitivity analyses. ${ }^{11}$

The Baron and Kenny approach requires that three conditions be met: (1) The treatment (T) must have a statistically significant effect on the outcome (Y); (2) the treatment (T) must have a statistically significant effect on the mediator (M); and (3) the effect of the treatment $(\mathrm{T})$ on the outcome $(\mathrm{Y})$ has to be

\footnotetext{
${ }^{10}$ Vescio, Sechrist, and Paolucci (2003) test whether empathy mediates the relationship between perspective-taking and attitudes toward out-groups among undergraduate students.

${ }^{11}$ See SI-F for the analysis of the parallel encouragement design we preregistered.
}

significantly reduced when the mediator $(\mathrm{M})$ is included. The first condition is met for the thermometer outcome. Table 1 shows that the second and third conditions are met as well: treatment $(\mathrm{T})$ increases empathy for immigrants (M), and this empathy eliminates the treatment effect on the thermometer (Y).

This approach also requires that two assumptions hold: there must be no omitted variable bias in either column (2) or (3) in Table 1. We know that this is the case for column (2), since our family history treatment is randomly assigned. But for column (3), the sequential ignorability assumption is not directly testable. Instead, we offer two solutions. First, we control for all observable confounds, including gender, partisanship, age, education, and baseline empathy (Davis 1980), the last of which might most reasonably affect both mediator and outcome. Second, we implement the more generalized method proposed in Imai, Keele, and Tingley (2010) allowing us to assess how large the omitted variable bias would have to be to erase our average causal mediation effect.

Figure 4 shows a statistically significant average causal mediation effect for the immigration thermometer outcome, indicating that the treatment effect on favorability of immigrants is mediated by empathy. ${ }^{12}$

\footnotetext{
${ }^{12}$ We present sensitivity analyses (Cinelli and Hazlett 2020; Imai, Keele, and Tingley 2010) in SI-F.
} 
TABLE 1. Empathy for Immigrants Mediates Family History Treatment Effect

\begin{tabular}{|c|c|c|c|}
\hline & Stage 1: & Stage 2: & Stage 3: \\
\hline & $\begin{array}{l}\text { Treatment effect on } \\
\text { thermometer outcome }\end{array}$ & $\begin{array}{l}\text { Treatment effect on } \\
\text { empathy mediator variable }\end{array}$ & $\begin{array}{c}\text { Treatment effect on } \\
\text { thermometer outcome } \\
\text { controlling for mediator variable }\end{array}$ \\
\hline Family history treatment & $\begin{array}{l}2.08^{\star} \\
(0.85)\end{array}$ & $\begin{array}{c}0.19^{\star \star \star} \\
(0.04)\end{array}$ & $\begin{array}{c}0.29 \\
(0.76)\end{array}$ \\
\hline Empathy mediator & & & $\begin{array}{c}9.09^{\star \star *} \\
(0.35)\end{array}$ \\
\hline Constant & $\begin{array}{c}40.10^{\star \star *} \\
(2.75)\end{array}$ & $\begin{array}{c}4.91^{* * *} \\
(0.15)\end{array}$ & $\begin{array}{l}-3.86 \\
(3.07)\end{array}$ \\
\hline $\begin{array}{l}\text { Controls } \\
\text { Observations }\end{array}$ & $\begin{array}{c}\checkmark \\
3,810\end{array}$ & $\begin{array}{c}\checkmark \\
3,795\end{array}$ & $\begin{array}{c}\checkmark \\
3,795\end{array}$ \\
\hline
\end{tabular}

\section{FIGURE 4. Empathy Mediation of Family History Treatment}

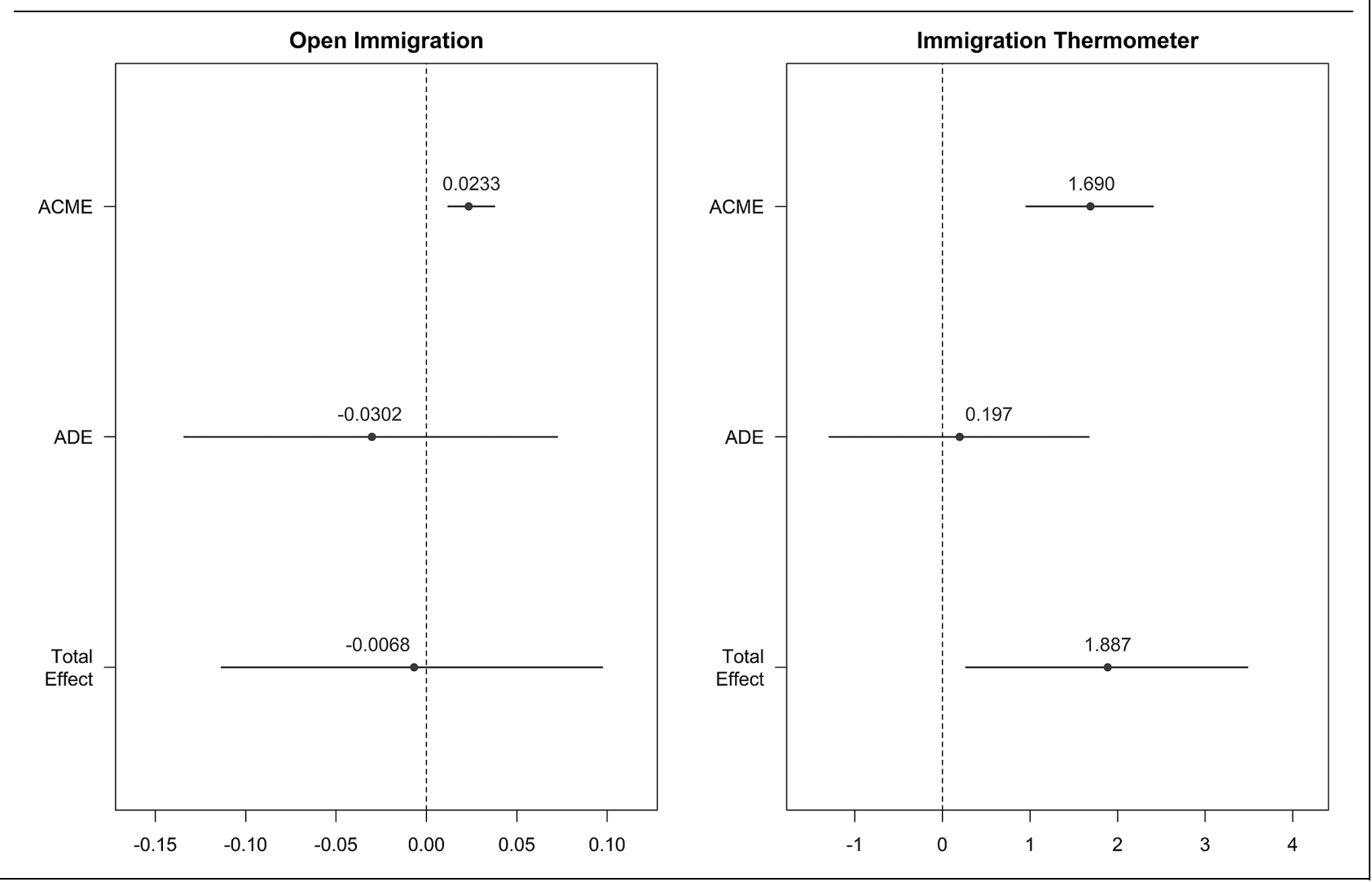

Our sensitivity analyses suggest that confounders as strong as baseline empathy are not sufficient to explain away the observed estimate. ${ }^{13}$

\footnotetext{
${ }^{13}$ In SI-J, we rely on the coding of our open-ended treatment question ("In one or two sentences, please tell us why your family came to the United States") to probe whether any of the other mechanisms highlighted by Todd and Galinsky (2014) might underlie our treatment effect.
}

\section{CONCLUSION}

This paper presents evidence that priming Americans on their family histories can increase support for open immigration policies and improve favorability of immigrants, pushing the needle towards greater inclusion. These effects occur across a range of subgroups, including supporters of President Trump. We also provide evidence that the treatment changes attitudes in part by increasing empathy for immigrants. 
These results contribute to a nascent body of research suggesting that individuals who possess a shared connection to the migrant experience are more likely to hold positive attitudes toward migrants. We show across three studies conducted over two years that even a light-touch treatment can meaningfully shift attitudes. These results align with prejudice reduction studies highlighting the effect of drawing attention to shared experiences between different communities (Motyl et al. 2011).

While our studies show compelling evidence that a family history narrative can shape attitudes toward migrants-suggesting that the power of perspectivetaking can extend via family relationships - they cannot adjudicate between the various mechanisms identified in the social psychology literature (Todd and Galinsky 2014). Indeed, we find evidence for one mechanism: empathy. But we do not test alternative mechanisms, such as shifting attributional thinking or self-out-group merging. Future studies should directly test the full menu of mechanisms in a real-world setting. Additionally, our treatment is unlikely to produce longer-term effects, given that it was designed to remind respondents temporarily about their own immigration histories.

Nonetheless, even relatively small and short-term effects could be relevant for practitioners prior to an election or an important vote in Congress, and highprofile politicians who emphasize this message in their rhetoric may be capable of prompting modest shifts for a large number of Americans. Furthermore, the evidence in this paper can inform efforts to create largerscale interventions capable of generating more lasting changes. Combining our findings with those of Feigenbaum, Palmer, and Schneer (2019), this type of priming may influence legislation by shaping the voting behavior of legislators themselves.

Finally, our findings have implications for the comparative study of migrant exclusion. Despite the polarization in public opinion toward migrants in the United States, Americans tend to hold more favorable attitudes than do citizens of many other countries (e.g., Gonzalez-Barrera and Connor 2019). The commonality of immigrant family histories in the United States may partially explain this pattern.

\section{SUPPLEMENTARY MATERIALS}

To view supplementary material for this article, please visit http://dx.doi.org/10.1017/S0003055420001057.

Replication materials can be found on Dataverse at: https://doi.org/10.7910/DVN/5UEEU2.

\section{REFERENCES}

Adida, Claire L., Adeline Lo, and Melina R. Platas. 2018. "Perspective Taking Can Promote Short-Term Inclusionary Behavior toward Syrian Refugees." Proceedings of the National Academy of Sciences 115 (38): 9521-6.

Baron, Reuben M., and David A. Kenny. 1986. "The ModeratorMediator Variable Distinction in Social Psychological Research:
Conceptual, Strategic, and Statistical Considerations." Journal of Personality and Social Psychology 51 (6): 1173-82.

Batson, C. Daniel, and Laura L. Shaw. 1991. "Evidence for Altruism: Toward a Pluralism of Prosocial Motives." Psychological Inquiry 2 (2): 107-22.

Broockman, David, and Joshua Kalla. 2016. "Durably Reducing Transphobia: A Field Experiment on Door-to-Door Canvassing." Science 352 (6282): 220-24.

Cinelli, Carlos, and Chad Hazlett. 2020. "Making Sense of Sensitivity: Extending Omitted Variable Bias." Journal of the Royal Statistical Society: Series B (Statistical Methodology) 82 (1): 39-67.

Dancygier, Rafaela M. 2010. Immigration and Conflict in Europe. New York: Cambridge University Press.

Davis, Mark H. 1980. "A Multidimensional Approach to Individual Differences in Empathy." JSAS Catalog of Selected Documents in Psychology 10: 85.

Dinas, Elias, Vasiliki Fouka, and Alain Schlapfer. Forthcoming. "Family History and Attitudes toward Out-Groups: Evidence from the European Refugee Crisis." Journal of Politics, https://doi.org/ 10.1086/710016.

Feigenbaum, James, Maxwell Palmer, and Benjamin Schneer. 2019 "Descended from Immigrants and Revolutionists': How Family Immigration History Shapes Legislative Behavior in Congress." Working Paper. https://www.hks.harvard.edu/publications/ descended-immigrants-and-revolutionists-how-familyimmigration-history-shapes.

Fraga, Luis R., and Gary M. Segura. 2006. "Culture Clash? Contesting Notions of American Identity and the Effects of Latin American Immigration." Perspectives on Politics 4 (2): 279-87.

Galinsky, Adam D., and Gordon B. Moskowitz. 2000. "PerspectiveTaking: Decreasing Stereotype Expression, Stereotype Accessibility, and In-Group Favortism." Journal of Personality and Social Psychology 78 (4): 708-24.

Glynn, Adam N., and Maya Sen. 2015. "Identifying Judicial Empathy: Does Having Daughters Cause Judges to Rule for Women's Issues?" American Journal of Political Science 59 (1): $37-54$.

Gonzalez-Barrera, Ana, and Phillip Connor. 2019. "Around the World, More Say Immigrants are a Strength Than a Burden." Pew Research Center, March 14. https://www.pewresearch.org/global/ 2019/03/14/around-the-world-more-say-immigrants-are-astrength-than-a-burden.

Hainmueller, Jens, and Daniel J. Hopkins. 2014. "Public Attitudes toward Immigration." Annual Review of Political Science 17: 225-49.

Hartman, Alexandra C., and Benjamin S. Morse. 2020. "Violence, Empathy, and Altruism: Evidence from the Ivorian Refugee Crisis in Liberia." British Journal of Political Science 50 (2): 731-55.

Hilburn, Jeremy, Wayne Journell, and Lisa Brown Buchanan. 2016. "A Content Analysis of Immigration in Traditional, New, and Non-Gateway State Standards for U.S. History and Civics." The High School Journal 99 (3): 234-51.

Hopkins, Daniel J., John Sides, and Jack Citrin. 2019. "The Muted Consequences of Correct Information about Immigration." The Journal of Politics 81 (1): 315-20.

Imai, Kosuke, Luke Keele, and Dustin Tingley. 2010. "A General Approach to Causal Mediation Analysis." Psychological Methods 15 (4): 309-34.

Kalla, Joshua L., and David E. Broockman. 2020. "Reducing Exclusionary Attitudes through Interpersonal Conversation: Evidence from Three Field Experiments." American Political Science Review 114 (2): 410-25.

Lo, Adeline, Scott Williamson, Claire Adida, Melina Platas, Lauren Prather, and Seth Werfel. 2020. "Replication Data for: Family Matters: How Immigrant Histories Can Promote Inclusion." Harvard Dataverse. Dataset. https://doi.org/10.7910/ DVN/5UEEU2.

Marshall, T. H. 1964. Class, Citizenship and Social Development. Chicago: University of Chicago Press.

Motyl, Matt, Joshua Hart, Tom Pyszczynski, David Weise, Molly Maxfield, and Angelika Siedel. 2011. "Subtle Priming of Shared Human Experiences Eliminates Threat-Induced Negativity toward Arabs, Immigrants, and Peace-Making." Journal of Experimental Social Psychology 47 (6): 1179-84. 
Okamoto, Dina, and Kim Ebert. 2016. "Group Boundaries, Immigrant Inclusion, and the Politics of Immigrant-Native Relations." American Behavioral Scientist 60 (2): 224-50.

Schildkraut, Deborah J. 2007. "Defining American Identity in the Twenty-First Century: How Much 'There' is There?" The Journal of Politics 69 (3): 597-615.

Sharrow, Elizabeth A., Jesse H. Rhodes, Tatishe M. Nteta, and Jill S. Greenlee. 2018. "The First-Daughter Effect: The Impact of Fathering Daughters on Men's Preferences for Gender-Equality Policies." Public Opinion Quarterly 82 (3): 493-523.

Shiffman, Dan. 1996. "A Standard for the Wise and Honest: The

'Americans All ... Immigrants All' Radio Broadcasts." Studies in Popular Culture 19 (1): 99-107.

Simonovits, Gabor, Gabor Kezdi, and Peter Kardos. 2018. "Seeing the World Through the Other's Eye: An Online Intervention Reducing Ethnic Prejudice." American Political Science Review 112 (1): 186-93.

Todd, Andrew R., and Adam D. Galinsky. 2014. "PerspectiveTaking as a Strategy for Improving Intergroup Relations:
Evidence, Mechanisms, and Qualifications." The History Teacher 8 (7): 374-87.

Vecoli, Rudolph J. 1996. "The Significance of Immigration in the Formation of an American Identity." The History Teacher 30 (1): 9-27.

Vescio, Theresa K., Gretchen B. Sechrist, and Matthew P. Paolucci. 2003. "Perspective Taking and Prejudice Reduction: The Mediational Role of Empathy Arousal and Situational Attributions." European Journal of Social Psychology 33 (4): 455-72.

Washington, Ebonya L. 2008. "Female Socialization: How Daughters Affect Their Legislator Fathers." American Economic Review 98 (1): 311-32.

Waters, Mary. 1990. Ethnic Options: Choosing Identities in America. Berkeley: University of California Press.

Wong, Tom K. 2016. The Politics of Immigration: Partisanship, Demographic Change, and American National Identity. New York: Oxford University Press. 